Gut, 1973, 14, 943-948

\title{
Plasma and urinary zinc in patients with malabsorption syndromes or hepatic cirrhosis
}

\author{
B. E. WALKER ${ }^{1}$, J. B. DAWSON, J. KELleher, AND M. S. LOSOWSKY \\ From the University Department of Medicine, St James's Hospital, and Department of Medical Physics, \\ University of Leeds, Leeds, England
}

SUMMARY Plasma and urinary zinc have been measured in 19 patients with malabsorption and 21 patients with hepatic cirrhosis. The results have been compared with those of 20 control subjects and 23 patients with a variety of other diseases. The diurnal variation in plasma zinc levels has been confirmed and is of such magnitude that this must be taken into account in comparing results in groups of subjects. Plasma zinc levels, both fasting and after a meal, are significantly lower in patients with cirrhosis $(71$ and $60 \mu \mathrm{g} / 100 \mathrm{ml})$ and malabsorption (76 and $64 \mu \mathrm{g} / 100 \mathrm{ml})$ than in controls (97 and $81 \mu \mathrm{g} / 100 \mathrm{ml}$ ). In the patients with cirrhosis or malabsorption similar correlations exist between plasma zinc and plasma albumin, suggesting that the low plasma zinc levels may be, at least in part, dependent on the plasma albumin level. Urinary zinc excretion is increased in cirrhosis, but not in malabsorption, indicating that increased urinary loss is unlikely to explain the low plasma levels.

Although zinc deficiency syndromes are well recognized in animals, it is only in recent years that the possible role of zinc in human nutrition has been investigated. This has largely resulted from the development of improved analytical methods, which with appreciation of the problems of contamination, suggest a re-evaluation of earlier conclusions (Davies, Musa, and Dormandy, 1968).

Lowered values for plasma, serum, or whole blood zinc have been reported in many apparently unrelated clinical conditions including infectious diseases, pernicious anaemia, leukaemias, malignant tumours, hepatocellular jaundice, chronic polyarthritis and chronic nephritis (Vikbladh, 1951), psoriasis, venous leg ulceration (Greaves and Boyde, 1967), carcinoma (Davies et al, 1968), myocardial infarction (Bottomley, Cornelison, Jacobs, and Lindeman, 1969), severe burns (Nielsen and Jemec, 1968), and after surgical operations(Henzel, DeWeese, and Pories, 1967). The wide range of these conditions suggests that a low plasma zinc may be a nonspecific effect of systemic illness (Greaves and Boyde, 1967), similar to changes which have been reported for plasma levels of copper and iron (Underwood, 1962). A further problem is that other workers have

'Please address correspondence to: Dr B. E. Walker, Department of Medicine, St James's Hospital, Leeds, LS9 7TF.

Received for publication 25 September 1973. been unable to confirm some of these results (Davies et al, 1968; Withers, Baker, Musa, and Dormandy, 1968).

It is, however, agreed that a more specific abnormality of zinc metabolism occurs in patients with hepatic cirrhosis. In cirrhosis of the liver serum zinc levels may be low (Vallee, Wacker, Bartholomay, and Hoch, 1957; Fredricks, Tanaka, and Valentine, 1960; Kahn, Helwig, Redeker, and Reynolds, 1965) and urinary zinc increased (Vallee et al, 1957; Sullivan, 1962; Kahn et al, 1965) and these values may be returned to normal by oral zinc supplements (Vallee et al, 1957). Most of the reported results have been in patients with alcoholic cirrhosis and it may be that lowered serum zinc is related to alcoholism rather than to cirrhosis (Sullivan and Lankford, 1965). There is evidence of a correlation between serum zinc levels and the severity of liver damage (Kahn et al, 1965), the serum zinc in liver disease correlating particularly with the serum albumin level (Kahn et al, 1965). At physiological pH, zinc in plasma is protein bound (Berfenstam, 1952), part firmly bound to globulin, and part loosely bound to albumin (Vikbladh, 1951). It is therefore possible that the reduced plasma levels of zincfound in patients with cirrhosis may be a reflection of the reduced albumin concentration commonly found in such patients.

To study these relationships further, plasma and 
urinary zinc levels have been measured in patients with cirrhosis and have been compared with the results obtained in patients with varying degrees of intestinal malabsorption, in whom the serum albumin showed considerable variation from normal.

\section{Methods and Patients Studied}

\section{METHODS}

Plasma and urine samples were collected and analysed for zinc content by atomic absorption spectroscopy, as previously described (Dawson and Walker, 1969). Plasma zinc was estimated after an overnight fast $(09.00 \mathrm{hr})$ and one hour after the usual midday meal (13.00 hr). Both samples were collected and estimated on the same day. Each sample was analysed for zinc content in triplicate, in order to minimize errors due to contamination.Twenty-fourhour urine samples were collected into acid-washed polystyrene containers, and results are the mean of at least two separate collections. In two patients, reliable urine collections could not be made.

Serum albumin was estimated by the method of Northam and Widdowson (1967) and faecal fat on seven-day collections whilst on a full balance regime by the method of Van de Kamer, Huinink, and Weyers (1949) using continuous faecal marking with chromic oxide. All patients were studied on a metabolic ward, ensuring the utmost accuracy for collecting specimens.

\section{PATIENTS}

Twenty-one patients with histologically proven cirrhosis of the liver were studied. Only two patients gave a history of excessive alcohol intake, one patient had active chronic hepatitis, and one primary biliary cirrhosis. All others were considered to have cryptogenic cirrhosis. One patient had undergone portacaval anastomosis four years before study. All patients were ambulant as this is a prerequisite for admittance to our metabolic ward. None had severe encephalopathy, and no drugs were given during the period of investigation or during the days immediately beforehand.

Nineteen patients with steatorrhoea (faecal fat output greater than $7 \%$ of the dietary intake) were studied (group I). Of these 19 patients, six had had a gastrectomy and were fully investigated (including jejunal biopsy) to exclude associated disease, four had histologically proven Crohn's disease, three had had small intestinal resections, two had ulcerative colitis, two had gluten-sensitive enteropathy proven by jejunal biopsy, one had multiple jejunal diverticula, and one had obstructive jaundice. Group II consists of 23 patients with a variety of disorders without steatorrhoea or cirrhosis. Ten of these patients were investigated because of diarrhoea (two after gastrectomy, one due to lactose intolerance, one surgical resection, and six were unexplained), five because of abdominal pain (one with pancreatitis, one gastric ulcer, three unexplained) and two because of anaemia (one due to dietary iron deficiency, one due to postgastrectomy iron deficiency). The remaining six consisted of one each of the following: rheumatoid arthritis, oedema of unknown cause, dermatitis herpetiformis, gluten-sensitive enteropathy, vitamin D deficiency, and hypopituitarism.

The results in the patients have been compared with results obtained in 20 normal subjects.

\section{Patients}

HEPATIC CIRRHOSIS

The results of plasma zinc determinations in the 21

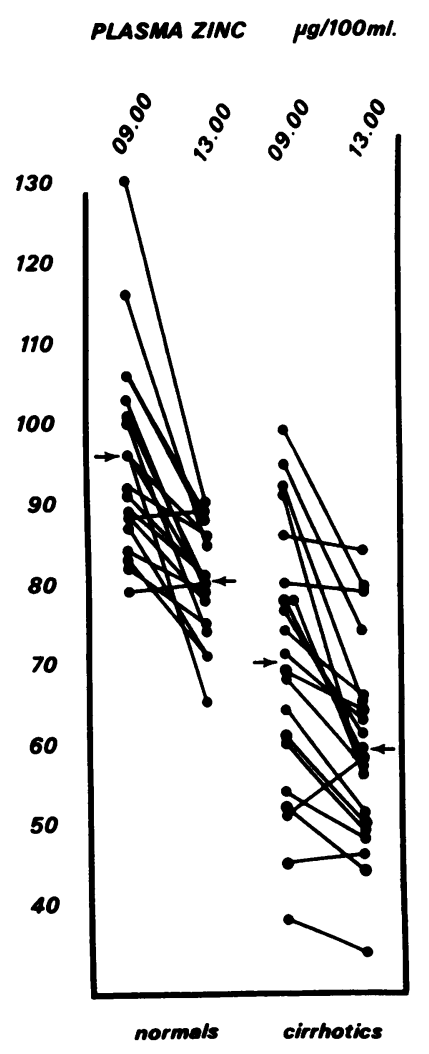

Fig 1 The plasma zinc measured after an overnight fast $(09.00 \mathrm{hr})$ and following the midday meal $(13.00 \mathrm{hr})$ in a group of normal subjects and a group of patients with hepatic cirrhosis. The arrows indicate the mean value for each group. The lines connect values from individual patients. 
patients with cirrhosis and 20 normal subjects are shown in figure 1 . Nineteen of the 21 patients had a lower plasma zinc level at $13.00 \mathrm{hr}$ compared with the fasting value at $09.00 \mathrm{hr}$. The finding of a higher fasting zinc level compared to a midday sample is similar to the results found in 18 of the 20 normal subjects.

The mean plasma zinc at $09.00 \mathrm{hr}(71 \mu \mathrm{g} / 100 \mathrm{ml})$ in the cirrhotic group is significantly less $(t=5 \cdot 4$, $P<0.001)$ than the corresponding level for normal subjects $(97 \mu \mathrm{g} / 100 \mathrm{ml})$. Only six of the 21 patients with cirrhosis had a value greater than the lowest recorded for the normal group. There was also a significant $(t=6.6, P<0.001)$ reduction in the plasma zinc level of the cirrhotic group at $13.00 \mathrm{hr}$ $(60 \mu \mathrm{g} / 100 \mathrm{ml})$ compared with normals $(81 \mu \mathrm{g} / 100$ $\mathrm{ml})$. The mean percentage fall in the plasma zinc between $09.00 \mathrm{hr}$ and $13.00 \mathrm{hr}$ was similar in normals $(16 \%)$ and cirrhotics $(15 \%)$.

The urinary zinc output per $24 \mathrm{hr}$ in the cirrhotic and normal group is shown in figure 2 . The mean value for the cirrhotic group $(703 \mu \mathrm{g} / 24 \mathrm{hr})$ is significantly higher $(t=2.1, P<0.05)$ than the

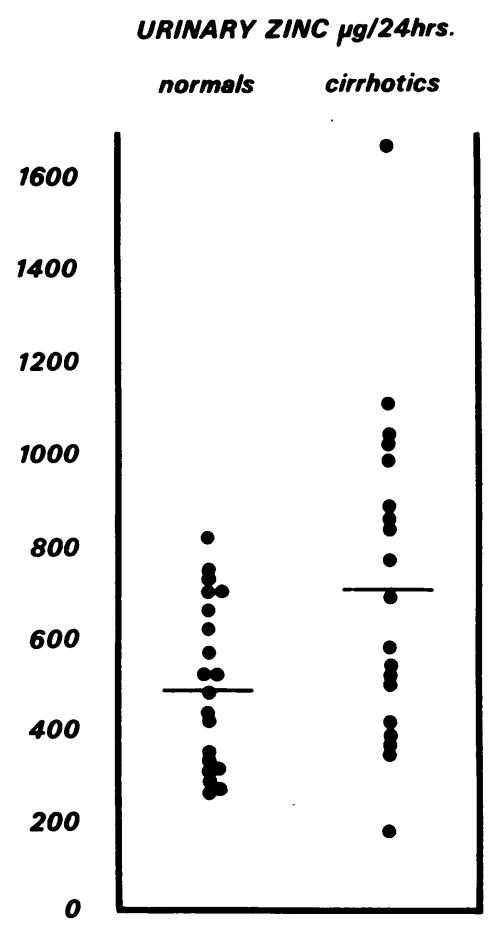

Fig 2 The daily urine output of zinc in a group of patients with hepatic cirrhosis compared with a group of normal subjects. The mean value for each group is indicated by the horizontal lines. corresponding value for the normal group (500 $\mu \mathrm{g} / 24 \mathrm{hr}$ ). There was, however, a wide variation in the urinary zinc output for the cirrhotic group, the lowest value being $187 \mu \mathrm{g} / 24 \mathrm{hr}$ and the highest $1670 \mu \mathrm{g} / 24 \mathrm{hr}$. For the cirrhotic group there was no significant correlation between the plasma zinc level at $09.00 \mathrm{hr}$ or $13.00 \mathrm{hr}$ and the urinary zinc output per $24 \mathrm{hr}(\mathrm{P}>0 \cdot 1)$.

The correlation between the plasma albumin and plasma zinc $(09.00 \mathrm{hr})$ in patients with cirrhosis is shown in figure 3 . The mean plasma albumin for the group was $3.5 \mathrm{~g} / 100 \mathrm{ml}$. There was a highly significant correlation between the fasting plasma zinc and albumin $(r=0.70, P<0.001)$. The correlation of plasma zinc at $13.00 \mathrm{hr}$ and plasma albumin was also highly significant $(r=0.76, P<0.001)$. The correlation between the plasma albumin and the urinary zinc output was not significant $(P>0.01)$.

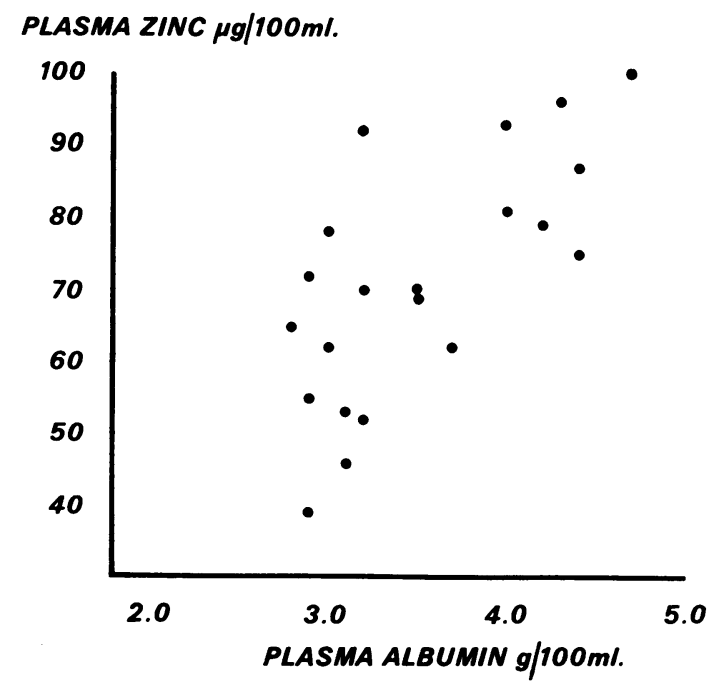

Fig 3 Relationship between plasma zinc $(09.00 \mathrm{hr})$ and plasma albumin for the patients with hepatic cirrhosis.

MALABSORPTION SYNDROME (GROUP I)

The results of the plasma zinc determinations at $09.00 \mathrm{hr}$ and $13.00 \mathrm{hr}$ in these patients compared with the normal group are shown in figure 4. The mean plasma zinc at $09.00 \mathrm{hr}$ is $76 \mu \mathrm{g} / 100 \mathrm{ml}$ which is significantly less than the corresponding value for normal subjects $(\mathrm{t}=4.4, \mathrm{P}<0.001)$. Similarly the plasma zinc at $13.00 \mathrm{hr}(64 \mu \mathrm{g} / 100 \mathrm{ml})$ is also significantly lower than the figure for the normal group $(\mathrm{t}=4.2, \mathrm{P}<0.001)$.

The mean plasma albumin in group I was 3.5 


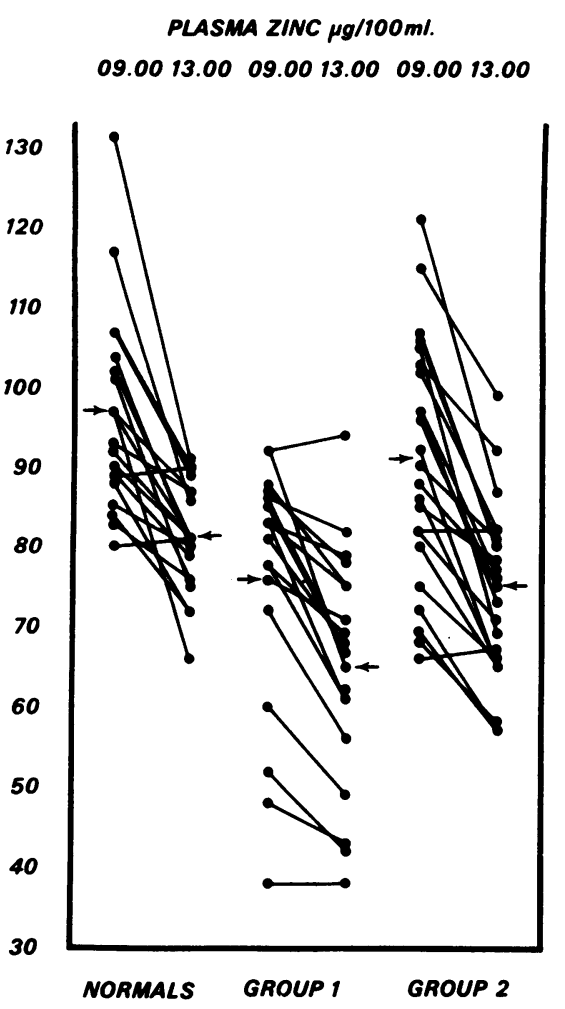

Fig 4 The plasma zinc measured after an overnight fast $(09.00 \mathrm{hr})$ and following the midday meal $(13.00 \mathrm{hr})$ in a group of normal subjects, in a group of patients with malabsorption (group I), and in a group of patients with miscellaneous diseases (group II) other than cirrhosis or malabsorption. Arrows indicate meanvalues for each group. The lines connect values for individual patients.

$\mathrm{g} / 100 \mathrm{ml}$, the same as in the cirrhotic group. The correlation between the plasma albumin and plasma zinc at $09.00 \mathrm{hr}$ for group $\mathrm{I}$ is shown in figure 5. The correlation is highly significant $(r=0.76, \mathrm{P}<0.001)$. There was no significant difference between the regression coefficients for plasma zinc and plasma albumin for the cirrhotic and group I patients.

There was no significant correlation between the faecal fat excretion and plasma zinc level $(09.00 \mathrm{hr})$ for group I patients $(r=0.27, \mathrm{P}>0.09)$.

The mean urinary zinc excretion for this group was $463 \mu \mathrm{g} / 24 \mathrm{hr}$, which was not significantly different from the normal group (500 $\mu \mathrm{g} / 24 \mathrm{hr})$.

MISCELLANEOUS GROUP (GROUP II)

The results of the plasma zinc determinations at $09.00 \mathrm{hr}$ and $13.00 \mathrm{hr}$ in these patients is shown

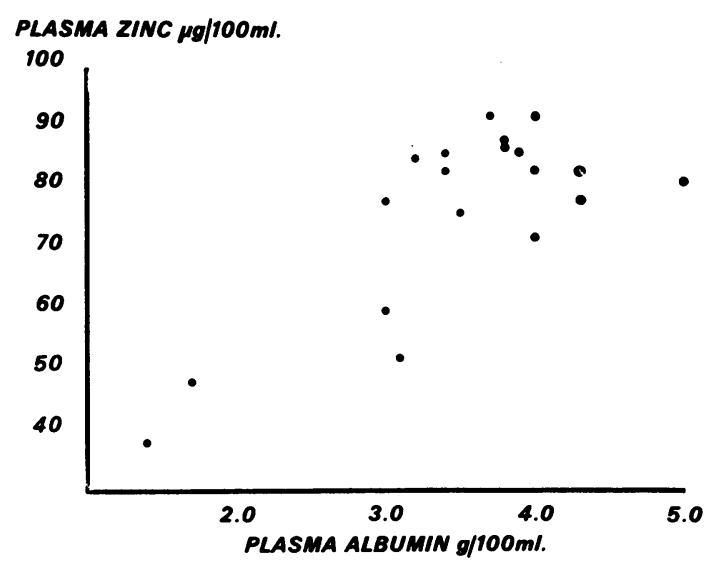

Fig 5 Relationship between plasma zinc $(09.00 \mathrm{hr})$ and plasma albumin for the patients with malabsorption, whose faecal fat exceeded $7 \%$ of dietary fat intake (group I).

in figure 4. The mean plasma zinc is lower than in the normal subjects at $09.00 \mathrm{hr}(90 \mu \mathrm{g} / 100 \mathrm{ml})$ and at $13.00 \mathrm{hr}(74 \mu \mathrm{g} / 100 \mathrm{ml})$ although only the latter of these values is significantly different from normal $(t=1.5, P>0.1$ and $t=2.3, P<0.05$ respectively). Four of the patients in this group had plasma zinc levels at $13.00 \mathrm{hr}$ which were lower than the lowest value in the control group. The diagnoses in these four were rheumatoid arthritis, oedema of unknown cause, dermatitis herpetiformis, and gastric ulcer. The plasma albumin levels in these patients were $4.4,3 \cdot 3,4.4$, and $3.0 \mathrm{~g} \%$ respectively. The mean plasma albumin for the group $(4 \cdot 2 \mathrm{~g} / 100 \mathrm{ml})$ was not significantly different from the control group. There was no correlation between the plasma albumin and plasma zinc in this group ( $\mathrm{r}=0.2, \mathrm{P}>0.9)$.

The mean urinary zinc in this group $(434 \mu \mathrm{g} / 24 \mathrm{hr})$ was not significantly different from the normals.

\section{Discussion}

There is considerable evidence that in normal subjects the fasting plasma zinc is significantly higher than the value approximately one hour after a meal (Vikbladh, 1951; Davies et al, 1968; Withers et al, 1968; Dawson and Walker, 1969). McBean and Halstead (1969), however, were unable to demonstrate any statistical difference between fasting plasma zinc and the value one hour after a meal. Davies et al (1968) found a significant fall in plasma zinc within $10 \mathrm{~min}$ of drinking $50 \mathrm{~g}$ of glucose, both in patients with a variety of diseases, including malabsorption, and normals, the values returning to 
fasting levels within two hr, and being independent of plasma dilution. We have found that both in normal subjects and in patients with cirrhosis of the liver or malabsorption syndromes a reduction in plasma zinc at $13.00 \mathrm{hr}$ as compared with the fasting value is remarkably consistent. It is of considerable importance to take this into account when comparing values from different groups of subjects.

The plasma zinc levels in our patients with cirrhosis both at $09.00 \mathrm{hr}$ and at $13.00 \mathrm{hr}$ were significantly lower than the corresponding values in normal subjects. This is in agreement with the results of other workers (Vallee, Wacker, Bartholomay, and Robin, 1956; Fredricks et al, 1960; Kahn et al, 1965). So far as we could ascertain none of the patients in this group was a chronic alcoholic and thus it seems unlikely that the low plasma zinc level is dependent on alcoholism or an alcoholic aetiology for cirrhosis. The significant correlation between the plasma zinc and serum albumin level, in agreement with the work of Vallee et al (1957) and Kahn et al (1965), might reflect that plasma zinc is dependent on the severity of hepatic dysfunction but might equally represent a more direct relationship between zinc and albumin levels not depending on hepatic function. It may be, however, that the low plasma zinc level represents a depletion of body stores since the zinc content of cirrhotic liver is low, even allowing for its content of fibrous tissue (Boyett and Sullivan, 1970a).

The urinary excretion of zinc was significantly higher in the patients with cirrhosis than in the normal subjects and eight of the patients had a zinc excretion in excess of the highest value found in a normal subject. The range of zinc excretion in this group was, however, wide. The lack of correlation between the plasma zinc and urinary zinc makes it unlikely that the low plasma value is the result of excessive urinary loss. Even in the patients with the highest urinary zinc, this would still represent only a small proportion of total zinc excretion by the body since the major route of excretion is the gastrointestinal tract.

Kahn et al (1965) found elevated urinary zinc more frequently in those patients who were clinically more severely ill, although there was no correlation between the presence of ascites and zinc excretion or between the presence of ascites and the serum level of zinc. Sullivan (1962), however, found some correlation between the presence of ascites and increased zinc excretion, but thought it more logical to relate both these abnormalities to the hepatic dysfunction. In the present work no correlation was found between the urinary excretion of zinc and either the plasma zinc level or the serum albumin. Furthermore, the patient who had the highest zinc excretion had minimal ascites, but three other patients with marked ascites had zinc excretions within the normal range. Sullivan and Heaney (1970) have found, in alcoholic liver disease, that an increased renal clearance of zinc was found in all patients regardless of the serum level and it would therefore seem that different mechanisms may be responsible for the low plasma zinc and the increased urinary zinc.

Patients with malabsorption are likely to suffer from deficiences of electrolytes, trace elements, and vitamins due to inadequate absorption and excessive loss from the gastrointestinal tract. MacMahon, Parker, and McKinnon (1968) have reported two patients suffering from malabsorption syndromes in whom there was biochemical evidence of zinc deficiency, and who appeared to respond to oral zinc therapy although in both cases other treatment was given at the same time. To our surprise, we have found no survey of the zinc status of a large group of patients suffering from malabsorption.

The patients in group I, all of whom had steatorrhoea, showed plasma zinc levels both at $09.00 \mathrm{hr}$ and $13.00 \mathrm{hr}$ significantly lower than the corresponding values for normal subjects. The urinary zinc was, however, not significantly different from that of the controls. The mean plasma albumin level in group I was the same as in the group with cirrhosis, and in both cases there was a significant correlation between the plasma zinc levels and serum albumin. In cirrhosis plasma zinc and albumin levels might both be low as a result of reduced hepatic function perhaps reflecting low levels of a specific zinc-binding protein or the reduced plasma zinc may be consequent upon the reduced serum albumin level. The latter would seem to be the more likely explanation since we have found a similar reduction in plasma zinc levels in patients with malabsorption who also have a lowered serum albumin level which is almost certainly not consequent upon liver disease. The lowered plasma zinc in liver disease might be related to the malabsorption which occurs in cirrhosis of the liver (Losowsky and Walker, 1969) but this seems unlikely since the low plasma zinc levels occur in a higher proportion of patients than does steatorrhoea. In any case it is hard to see how the high urinary zinc in cirrhosis could be attributed to malabsorption and this appears to be a finding specific to liver disease since similar findings occur in hepatitis without a low serum level (Kahn et al, 1965). A direct relationship between plasma zinc and albumin levels is supported by a similar correlation in patients with protein calorie malnutrition (Hansen and Lehmann, 1969). Boyett and Sullivan (1970b) have shown that in patients with cirrhosis there is a close correlation between total serum zinc concentration and albu- 
min-bound zinc and remarkably little change in globulin-bound zinc. A fall in plasma zinc might thus follow a reduction in albumin concentration.

The possibility that abnormalities of protein metabolism may occur secondary to zinc deficiency must also be considered as a possible explanation of the relationship between plasma zinc and plasma albumin. Hove, Elvehjem, and Hart (1937) have shown that in some zinc-deficient rats the total serum proteins are lower than in normal animals and it has also been found that zinc deficiency results in impaired protein and deoxyribonucleic acid synthesis (Underwood, 1962). In patients with cirrhosis or malabsorption it is unlikely that the low plasma albumin is solely a consequence of zinc deficiency since in cirrhosis albumin synthesis is diminished (Wilkinson and Mendall, 1963) and in malabsorption intestinal loss of albumin is increased (Jeejeebhoy, 1964). Furthermore low plasma zinc levels have been described in a wide variety of conditions which are not usually associated with low plasma albumin levels. It may be that some of the low plasma values reported in these diseases are due to failure to take into account the diurnal variation. However, we have confirmed that in some patients with disorders other than cirrhosis or malabsorption low plasma zinc levels may occur, even in the presence of a normal plasma albumin level, indicating that there are factors in addition to plasma albumin level which determine the plasma zinc level.

\section{References}

Berfenstam, R. (1952). Studies on blood zinc. Acta paediat. (Uppsala), 41, Suppl. 87.

Bottomley, R. G., Cornelison, R. L., Jacobs, L. A., and Lindeman, R. D. (1969). Zinc metabolism following acute tissue injury in man. J. Lab. clin. Med., 74, 852.

Boyett, J. D, and Sullivan, J. F. (1970a). Zinc and collagen content of cirrhotic liver. Amer. J. dig. Dis., 15, 797-802.

Boyett, J. D., and Sullivan, J. F. (1970b). Distribution of proteinbound zinc in normal and cirrhotic serum. Metabolism, 19, 148-157.

Davies, I. J. T., Musa, M., and Dormandy, T. L. (1968). Measurements of plasma zinc. J. clin. Path., 21, 359-365.

Dawson, J. B., and Walker, B. E. (1969). Direct determination of zinc in whole blood, plasma and urine by atomic absorption spectroscopy. Clin. chim. Acta, 26, 465-475.
Fredricks, R. E., Tanaka, K. R., and Valentine, W. N. (1960). Zinc in human blood cells: normal values and abnormalities associated with liver disease. J. clin. Invest., 39, 1651-1656.

Greaves, M., and Boyde, T. R. C. (1967). Plasma-zinc concentrations in patients with psoriasis, other dermatoses, and venous leg ulceration. Lancet, 2, 1019-1020.

Hansen, J. D. L., and Lehmann, B. H. (1969). Serum zinc and copper concentrations in children with protein-calorie malnutrition. S. Afr. med. J., 43, 1248-1251.

Henzel, J. H., DeWeese, M. S., and Pories, W. J. (1967). Significance of magnesium and zinc metabolism in the surgical patient. Arch. Surg., 95, 991-999.

Hove, E., Elvehjem, C. A., and Hart, E. B. (1937). The physiology of zinc in the nutrition of the rat. Amer. J. Physiol., 119, 768-775.

Jeejeebhoy, K. N. (1964). Hypoanabolic hypoalbuminaemia in gastro-intestinal disease, Brit, med. $J, 1,30-35$.

Kahn, A. M., Helwig, H. L., Redeker, A. G., and Reynolds, T. B. (1965). Urine and serum zinc abnormalities in disease of the liver. Amer. J. clin. Path., 44, 426-435.

Kamer, J. H. Van de, Huinink, H., Ten Bokkel, and Weyers, H. A. (1949). Rapid method for the determination of fat in feces. J. biol. Chem., 177, 347-355.

Losowsky, M. S., and Walker, B. E. (1969). Liver disease and malabsorption. Gastroenterology, 56, 589-600.

McBean, L., and Halsted, J. A. (1969). Fasting versus postprandial plasma zinc levels. J. clin. Path., 22, 623.

MacMahon, R. A., Parker, M. L. M., and McKinnon, M. C. (1968). Zinc treatment in malabsorption. Med. J. Aust., 2, 210-212.

Nielsen, S. P., and Jemec, B. (1968). Zinc metabclism in patients with severe burns. Scand. J. plast. reconstr., Surg., 2, 47-52.

Northam, B. E., and Widdowson, G. M. (1967). The determination of serum albumin by AutoAnalyzer using bromcresol green. (Association of Clinical Biochemists Scientific and Technical Committee Study Group on Automation in Clinical Chemistry). Ass. clin. Biochem. tech. Bull. No. 11, pp. 1-7.

Sullivan, J. F. (1962). The relation of zincuria to water and electrolyte excretion in patients with hepatic cirrhosis. Gastroenterology, 42, 439-442.

Sullivan, J. F., and Heaney, R. P. (1970). Zinc metabolism in alcoholic liver disease. Amer. J. clin. Nutr., 23, 170-177.

Sullivan, J. F., and Lankford, H. G. (1965). Zinc metabolism and chronic alcoholism. Amer. J. clin. Nutr., 17, 57-63.

Underwood, E. J. (1962). Trace Elements in Human and Animal Nutrition, 2nd ed. Academic Press, New York and London.

Vallee, B. L., Wacker, W. E. C., Bartholomay, A. F., and Hoch, F. L. (1957). Zinc metabolism in hepatic dysfunction. II. Correlation of metabolic patterns with biochemical findings. New Engl. J. Med., 257, 1055-1065.

Vallee, B. L., Wacker, W. E. C., Bartholomay, A. F., and Robin, E. D. (1956). Zinc metabolism in hepatic dysfunction. I. Serum zinc concentrations in Laennec's cirrhosis and their, validation by sequential analysis. New Engl. J. Med., 255 403-408.

Vikbladh, I. (1951). Zinc in the mammalian organism. Scand. J. clin. Lab. Invest., 3, Suppl. 2, 1-74.

Wilkinson, P., and Mendenhall, C. L. (1963). Serum albumin turnover in normal subjects and patients with cirrhosis measured by ${ }^{131}$ I labelled human albumin. Clin. Sci., 25, 281292.

Withers, A. F. D., Baker, H., Musa, M., and Dormandy, T. L. (1968). Plasma-zinc in psoriasis. Lancet, 2, 278. 